\title{
Influences on Food Away from Home Feeding Practices Among English and Spanish Speaking Parent-Child Dyads
}

\author{
Authors: Courtney A. Pinard, Carmen Byker, \\ Samantha M. Harden, Leah R. Carpenter, Elena L. \\ Serrano, Daniel J. Schober, and Amy L. Yaroch
}

This is a postprint of an article that originally appeared in Journal of Child and Family Studies on September 10, 2014. The final publication is available at Springer via http://dx.doi.org/10.1007/s10826-014-0011-8

Pinard, Courtney A., Carmen Byker, Samantha M. Harden, Leah R. Carpenter, Elena L. Serrano, Daniel J. Schober, and Amy L. Yaroch. "Influences on Food Away from Home Feeding Practices Among English and Spanish Speaking Parent-Child Dyads." Journal of Child and Family Studies 24, no. 7 (July 18, 2014): 2099-2106. doi:10.1007/s10826-014-0011-8. 
1 Influences on Food Away From Home Feeding Practices among English and Spanish Speaking Parent-

2 Child Dyads

3 Running Title: Parent-Child Dyads FAFH

4

5 Authors: Pinard, C.A. ${ }^{1}$, Byker, C. ${ }^{2}$, Harden, S.M. ${ }^{3}$, Carpenter, L.R. ${ }^{1}$, Serrano, E.L. ${ }^{4}$, Schober, D.J. ${ }^{1}$, 6 Yaroch, A.L. ${ }^{1}$

7

$8{ }^{1}$ Gretchen Swanson Center for Nutrition, 8401 West Dodge Road, Suite 100, Omaha NE, 68114*

$9 \quad{ }^{2}$ Department of Food and Nutrition and Sustainable Food Systems, 222 Romney Gym

10 Montana State University, Bozeman MT, 59717-3360

$11{ }^{3}$ School of Kinesiology, 122- 6081 University Blvd., University of British Columbia, Vancouver BC, 12 V6T 1Z1 Canada

$13{ }^{4}$ Department of Human Nutrition, Foods and Exercise, 201 Wallace Annex, Virginia Polytechnic

14 Institute and State University, Blacksburg VA, 24060

15

$16 *$ interviews were conducted at this location 


\section{Abstract}

18 Background: Families are increasingly consuming food away from home (FAFH), contributing to 19 increased daily energy consumption and the obesity epidemic. The interplay between feeding styles 20 and co-decision making between parent-child dyads when eating FAFH is not understood. The present 21 study describes in-depth qualitative information about influential factors related to family feeding 22 practices (e.g., parenting style) among low-income English and Spanish speaking families with school23 aged children when eating FAFH.

24 Method: 20 parent-child dyads (10 English-speaking, 10 Spanish-speaking) completed key-informant

25 interviews. Interviews were recorded and transcribed verbatim. The constant comparison methodology 26 was utilized to analyze the data and interviews were independently coded for meaning units by two 27 coders. The preliminary meaning units and codes were analyzed by the coders and organized into 28 common categories.

29 Results: Themes that emerged from the interviews included: decision making when dining out, 30 parental practices and feeding style, use of and opinions about kid's menus, and overall influences on 31 food choices. Many parents had recommendations for healthier kid's menu options and overall, 32 Spanish-speaking families tended to eat out fewer times a week and cooked more family meals. 33 Conclusions and implications: This research elucidated rules and policies set by parents around food 34 away from and inside the home as well as the factors that influenced ordering at restaurants.

35 Decision-making between parent-child dyads about menu ordering at restaurants is complex. The 36 results of this study can be considered for future research in understanding the decision-making 37 process for English- and Spanish- speaking parent-child dyads when ordering from a restaurant menu. 38 
42 Tracing the etiology of childhood obesity is complex and improving the healthfulness of the American

43 diet has become a national health priority (1-3). The U.S. Department of Agriculture (USDA)

44 estimates that between 1985 and 2000, the daily per capita energy consumption increased by $12 \%$, or

45300 calories per day among American adults (4). One trend that has contributed to increased caloric

46 consumption is more frequent consumption of food away from home (FAFH). In 1970, only 34\% of a

47 family's food budget was accounted for by FAFH, and by the late 1990s this rose to more than $47 \%$

48 (5). The types of foods and drinks children order when consuming FAFH can ultimately impact their

49 overall diet and health. The effects of FAFH on diet and health depend on a number of factors,

50 including frequency of eating away from home, choice of restaurant (i.e., quick-service versus full-

51 service), foods ordered and consumed, and in the case of children, food rules established and enforced

52 by parents or caregivers (herein referred to as parents) (6-8). Additionally, low-income families tend to

53 consume more energy-dense, nutrient-poor foods than their higher-income families (3).

54

55 The degree to which both children and parents influence the decision making around FAFH restaurant 56 and meal selection is still unknown (9). Several studies have found an association between parenting 57 style and/or specific feeding practices (e.g., pressure to eat, restriction, availability, parental modeling, 58 and specific dietary behaviors) (10-12). The authoritative parenting style may be more conducive to 59 healthier food choices because limits, consequences, and expectations are set while demonstrating 60 warmth and support $(13,14)$. In contrast, authoritarian parenting styles are defined by high demands for 61 self-control but low levels of sensitivity $(13,14)$. Further, feeding practices differ across ethnic and 62 cultural groups. For example, Latino parents have been found to engage in an indulgent feeding style, 63 one that is characterized by warmth and acceptance in conjunction with a lack of monitoring of the 64 child's behavior $(15,16)$. Another study demonstrated that, among Latino families, those that ate more 65 frequently at Anglo-oriented restaurants (e.g., fast-food chains, buffets) were at higher risk for obesity 66 (17). Additionally, Latino parents with authoritarian feeding styles were more likely to have children 67 who were at risk for unhealthy eating (18).

69 To date, few studies have been conducted to examine the intersection between parenting style and 70 feeding practices and FAFH, including parent-child dynamics and decision-making, particularly 71 among Latinos. Little is known about how parent-child dyads interact and make ordering decisions at 72 restaurants. The purpose of this study was to obtain in-depth information about influential factors 
73 related to family feeding practices (e.g., parenting style) among low-income English and Spanish

74 speaking families with school-aged children when eating FAFH.

75

76 Method

77

78

\section{Recruitment}

79 Parent-child dyads were recruited through table tent advertising at a Mexican restaurant in a

80 predominantly Latino neighborhood in South Omaha; additional participants were recruited using

81 flyers placed across community and by word of mouth referrals. Parent-child dyads were eligible if the

82 child was between 8 and 13 years old. This particular age group was selected since our aim was to

83 recruit children old enough to make their own meal choices, but who may also receive significant

84 parental input with food choices. Recruitment efforts aimed to attract a representative sample of both

85 English- and Spanish- speaking Latino families (i.e., half of the dyads per dominant language).

86

87 Interviews

88 The authors developed a semi-structured interview guide based on a review of relevant literature 89 related to restaurant dining habits among families (19-21). Figure 1 displays the eight domains of

90 inquiry identified from the literature review for factors that may influence FAFH choices among

91 English- and Spanish-speaking parent-child dyads. These eight domains of inquiry spanned from acculturation influences to restaurant ordering behaviors (see Figure 1). In addition to the interviews, a

93 short demographic survey was collected that included self-reported height and weight which was

94 converted to Body Mass Index (BMI) for adults and BMI percentile for age and sex for children.

95 Following a phenomenological approach, the semi-structured interviews aimed to explore the in-depth

96 "lived experience" of how parent-child dyads co-constructed decisions when eating FAFH (22).

97 Beyond asking about typical family dining patterns and parental feeding style, two examples of key questions from the parent interview included: "What factors make it more likely that you and your family will eat out?" and "Please describe how you typically order dinner for your child (or teen) at a sit-down restaurant." For the child interviews, some key questions included: "What is your favorite food or meal to order when eating in a sit-down restaurant?", "Can you describe to me how your 102 dinner choice is made?", "What do you think your parents think about when choosing something for 103 you to eat when you are dining out?", and "What types of food/dishes do your mom/dad typically order 104 for themselves?". 
106 Bachelors and masters level research associates conducted separate interviews with parents and

107 children between April and December of 2012. Institutional Review Board approval was obtained from 108 the University of Nebraska Medical Center and written parental consent and child assent were obtained 109 onsite before the interviews began. Interviews were conducted at the research offices of the authors 110 and in the participating parent's preferred language (i.e., Spanish or English). All child interviews were 111 conducted in English, as all children were fluent in English. Interviews were conducted until 112 theoretical saturation. Each of the parent interviews lasted approximately 45 minutes, while the child 113 interviews (conducted concurrently and in a separate room from the parent) took approximately 20 114 minutes. Dyads received a \$20 gift card as an incentive for participating.

\section{Data Analysis}

117 Each interview was transcribed verbatim. Interviewers utilized constant comparison methodology (23) 118 and interviews were independently coded for meaning units by two coders (the lead author, CP, and 119 one other author for each interview) using the NVivo software package (Version 9, QRS International, 120 Victoria, Australia). The preliminary meaning units and codes were analyzed by the coders and 121 organized into common categories. These categories were examined for overlapping themes and 122 condensed to order the data. To maintain confidentiality, quotations reproduced in this paper have been 123 de-identified.

\section{Results}

127 In total, 20 parent-child dyads were interviewed $(\mathrm{N}=40)$, with ten English-speaking parents and ten 128 Spanish-speaking parents. All child interviews were conducted in English. Table 1 shows 129 sociodemographic information for participants. Adult BMI values ranged from 18.9 to 39.5 , with $22 \%$ 130 normal weight, 39\% overweight, and 39\% obese. The mean BMI percentile for children for age and 131 sex was 63 (children were asked for their height and weight and only 10 out of 20 respondents were 132 able to answer this). Household income ranged from less than $\$ 10,000$ per year to more than $\$ 100,000$ 133 per year, with the majority of participants reporting earning less than $\$ 50,000 /$ year). There was a span 134 of education levels. Four of the parent participants were male and the remainder $(\mathrm{N}=16)$ were female. 135 Adult participants ranged in age from under 21 years to 44 years of age. Children were between the 136 ages of 8 and $13(\overline{\mathrm{x}}=10.5, \mathrm{SD}=1.6)$ and $65 \%$ were male and $65 \%$ Latino. 
138 Themes and categories that emerged from the data are summarized in Table 2, including: decision 139 making when dining out, parental practices and feeding style, use of and opinions about kid's menus, 140 and overall influences on food choices. Within each of these broader themes, specific categories of 141 findings are explained below and summarized in Table 2.

143 Decision Making When Dining Out

144 Parents and children reported that the parent was responsible for selecting where the family will eat 145 out. One child stated, "My mom, she just picks." Several parents corroborated, "In my house, the food 146 is my decision."

148 The degree to which the parent had control over the child's meal choice varied. Many parent-child 149 dyads reported a combination of co-decision making processes for meal selection. One mother described the step-by-step process for ordering a meal for her child, "I ask her "what do you want to eat first?" The same mother then explained that after a child suggests a food, the parent responds, "Are you sure you want this to eat today? If she [the child] wants it she says yes. The decision is my daughter's." Many parents tended to give their children more autonomy in selecting their meal. Some of the parents who allowed their child to display autonomy when ordering conveyed their concern with cost of the meal $(n=12)$. One strategy that parents reported using to control cost was restricting their child's meal choice to the kids menu, "I don't really look at the price for the kids menu because they're pretty much the same, set prices, and just as long as it's something he's going to eat."

159 Conversely, some parents reported exerting control over the child's meal choice by giving guidance setting up parameters. One parent described this as, "We'll give the kids choices. We'll give them at

162 least two choices." A parent (Spanish-speaking) described how she influenced her children to order 163 healthier things, "[There are] three things they can choose. But then they have to choose vegetable. 164 For example, cooked vegetables or salad or French fries. I always choose salad or vegetables. So I 165 choose like that for them."

168 The majority of parents reported that rules and choices at home were stricter than when dining out, 169 “No, I think at a restaurant I'm more loose. At home, I'm more strict.” Many parents described allowing sugar sweetened beverages (SSBs) when dining out, but not at home, "Yeah, we don't buy 
171 like soda or anything like that, but whenever we go out, you know, the kids drink it." Children

172 corroborated this sentiment, agreeing that there were different rules for when they ate out when

173 compared to meals at home.

174

175 Almost all parents reported some limits on SSBs for their children. Parents reported limiting soda more 176 in the home than when dining out at a restaurant. One parent described, "Every once in a while I'll let 177 them drink pop, but not very often at a restaurant. [But at home] It's got to be like lemonade or water 178 or milk." Another parent described the added cost of SSBs, “We really don't drink soda, we drink 179 water. They can have a pop if we go out, and that all depends on money, cause I think soda's a rip 180 off." Similarly, one parent explained, “When eating out, I also discourage drinks because it's 181 expensive. However, for example, we go to fast food and the kids are getting a value meal, you know, 182 then your choices are usually a soda, a juice, or a milk, and I usually get a chocolate milk for the kids 183 then. I prefer for them not to get sodas in those situations."

185 Some of the parents $(\mathrm{n}=6)$ reported eating dinner as a family at a table, "So we're usually sitting at the table, we usually have dinner together ... every night but Wednesday night, ... Another parent reported, "The rules are that when we sit down to eat no one can leave the table if everyone has not finished". However, the majority of parents $(\mathrm{N}=14)$ reported eating meals not together at a table and typically in front of the television. This obesogenic feeding style was simply described by interviewees as normative practice, “We don't always sit at the table, we sometimes watch a movie-have a pizza and movie night”. One child reported, "Well, my dad, he lays in bed while we're eating. My mom she sits on the couch. Me and my brother sit at a table".

193 Several parents expressed concern about their child's weight, "I feel she's overweight. I do. [I feel it is 194 important for my child to have a desirable weight] it's important to me because when I was younger I 195 was teased and I don't want her to go through that." Another parent explained why she thought it was important for her son to be a healthy weight in terms of lifelong health and chronic disease risk, “...if 197 he stay[s] like that he will continue growing up with bad habits and will get fatter. I try to better him 198 because it is he who is going to suffer with the excess weight."

200 Some parents explained that they made efforts to role model healthy dietary behaviors, "I at least 201 order a salad with all my meals so maybe they'll eat it too." Another parent described the impact 202 positive role modeling may have on her child, "I take him into account because he is learning to make 203 his own decisions and I respect them." Similarly, another parent described the teachable moment of 
role modeling positive dietary behaviors, "I say to him, look how I do it. I say to him I am going to eat 205 it, its good."

207 Some parents reported using negotiation with their child to get them to eat more healthfully when 208 dining out. One parent described this as a struggle, "Well basically he is the child that will always try 209 to grab a bowl of cereal, like he doesn't want to eat the vegetables, or he's happier with a bag of chips. 210 When we're out, if he wants a dessert or something, I make him eat at least the vegetables and some of 211 the meat off of the plate. So that is kind of a battle sometimes." Another parent reported, "So 212 sometimes what we'll do, we'll negotiate and one of us will get the French fries and one of us will get 213 the vegetables, and then she'll have a little bit of it."

215 Some parents reported engaging in an authoritative feeding style, one that is encouraging, yet instructive. One child reported how his parents encourage him to choose healthier items, "They would need to tell me whether it's healthy, what it tastes like, and what's in it." A parent also explained how they described what foods are healthier to their children, "Explaining to him what is good for him. I would explain my motives. Like this will make you sick, this is not the right time to eat this food, or talk to him about the dish."

Several parents that appeared to align with an authoritative parenting style described how they provided choices for their children, “We've always given him a choice ever since he can talk. And I mean it's changed now, we give him a lot more free reign than he used to have. Another parent explained how she taught her children about self-regulation, "I've always tried to get her to listen to her body and to listen to what she's really hungry for." A few parents reported trying to educate their children about healthy eating/nutrition education with their children, "I have another son that, he's becoming overweight and we have diabetes in our family. Whenever we go grocery shopping, I'll show him the labels and he's starting to be able to read labels and understand that."

Several parents mentioned using food as a reward. One parent described, "I use pizza as something they have to earn." While some of the child respondents reported recognizing that their parents used of food as a reward, "They might have to bribe me, I'm not sure, otherwise I might just say no, but, umm, 234 I would probably get dessert." 
236 While some parents demonstrated a more "authoritative" feeding style $(\mathrm{n}=5)$ by setting guidelines and 237 parameters yet allowing their children to learn about the benefits of healthful choices, other parents 238 reported engaging in more negotiation $(n=4)$ and using food as a reward $(n=6)$.

240 Spanish-speaking parents (as compared to English-speaking parents) tended to eat out fewer times a week, and watched less TV, and cooked more healthfully at home. They described their home cooking to be healthier, "Well I prefer to cook at home because what I make is more economical, better, and everyone eats till they are full." Another parent responded, "In my house I always cook what is healthy and I try to get healthy foods that do not have a lot of fat but [high in] nutrition." One of the other parents described, "At home, the food that mama cooks gets eaten. And what I think is healthier for the children, but always when we go out...” The skill and tradition involved with home cooking was also emphasized, "My spouse is from El Salvador. So there is always rice and salad. I always cook what I have. Including if I'm missing an ingredient for a food that is supposedly traditional-I put another one in (laughter)."

\section{Use of and Opinions About Kids' Menu}

252 The selection from the kids' menu did not appear to be a concern among many parents and one child 253 described, "They don't care as long as it's on the children's menu." Overall, parents reported that 254 younger children ordered freely from the kids' menu $(n=7)$, while older children had outgrown the portion sizes and the flavors $(\mathrm{n}=5)$. Some parents of younger children suggested that the portion sizes were too large, "I think if they were portioned out better, I wouldn't mind them as much. But when you go out to the restaurants, it seems like it's bigger portions than what I would normally give them at home." However, parents of older children tended to advocate for larger portions, "It's not enough food for either one of my kids. They're both in their growth spurts or something; they eat like crazy." One potential solution suggested was to make smaller portions of adult items, "I think that they should choose food from the adult menu, but in smaller portions.

A few parents commented on the lack of availability of nutritious options when dining out. As one parent explained, "They're really not that healthy. You know they get the food groups there with added content of fat, salt, and everything ... and even some of the fast food places have applesauce or apples instead of fries, but generally they're not very healthy. " Many parents suggested including more fruits and vegetables and other healthy items, "I think they could sneak a lot more nutrition in than they do. I'm always trying to sneak in nutrition." Another parent described, "I think that they could have 
healthier options, like McDonalds getting the apples, but I think that they could have healthier

270 [options] and maybe not like the fries, they give them so many fries."

A few parents acknowledged that their child's food preferences were less healthy than they desired, "I know that his taste buds will develop and begin appreciating, craving different things. But I think he's on a little bit heavy of a pasta and cheese diet now. "Some children described willingness to try new foods when dining out, "Cause I think that you should try different [foods than] what you eat at home since it's a restaurant. Cause you're not going to eat at home; that's the reason that you're going to go somewhere else to eat something."

Most parent-child dyads reported using the kids' menu, in particular driven by price. However, parents expressed dissatisfaction with the healthfulness of the options on kids' menus and made several suggestions for improvement. Simultaneously, some parents were concerned about their child's BMI and recognized FAFH as a way to impact weight status. Current menu options cater to basic food preferences of children (24), but children also described a willingness to try new foods. There is an opportunity for restaurants to offer more healthful options on kids' menus, capitalizing on this willingness to try new foods. More healthful menus may result in beneficial sales for the restaurant, creating a mutually beneficial opportunity.

\section{Overall Influences on Food Choices}

Overall influences on food choices were comprised of five categories (Table 2). Children were asked if they could recall any food-related commercials on TV or online. They were able to identify several food-related commercials, thought they influenced their own food choices, and had negative feelings towards them. Children were easily able to identify food-related commercials, "I see McDonalds commercials a lot", and "Well they show BK and McDonalds." When asked if the food-related commercials make the child want specific foods, the child responded, "Well, I'd say $90 \%$ [of the time]." Most children expressed dislike towards commercials even though they influenced their choices, "They're really stupid actually so they're pointless."

At the same time, many parents expressed concern about the influences of food marketing on their child's dietary preferences, "He is picky, he's a big kid, he eats what he wants not what you want, if I give him a salad he will not eat it at all, if I give him a hotdog and chips he will eat it right away, its really difficult, you live here in America. It's hard. There are more commercials all the time and kid 
304 For most families in the current study, dining out was considered a treat, and not part of regular family meal patterns. However, some families in this study also reported eating fast food more regularly

Although cost and flavor were often ranked ahead of nutrition as competing factors when deciding where to eat, some parents did explain concern for nutrition, "Nutrition has to be like something healthy, not too much sugar and because he'd rather order a pop instead of milk or juice. So it has to be nutritious and the taste. It has to taste good in order to eat." With regard to their own nutrition

312 knowledge, some parents gained confidence through "Consult[ing] lots of books." Some books about 313 "Cholesterol fighting foods, foods that fight cholesterol" and others that include "practical, quick, healthy foods for the family." The participant stated that she was "Not an expert, but [she was] learning." Other parents were confident in their ability to identify nutritious meals and practices,

316 "Spaghetti, fish, vegetables, red meat, pork. They are nutritious because there are carbohydrates, proteins and vegetables."

\section{Discussion}

As an increasing number of families are consuming FAFH $(1,2)$, which can potentially result in added calories and poorer dietary outcomes (25). The current study obtained detailed qualitative data on parenting practices and decision-making among low-income English and Spanish speaking families with school-aged children when dining away from home. The themes and categories that emerged elucidated rules and policies set by parents around food away from and inside the home as well as the factors that influenced ordering at restaurants. For most families in the current study, dining out was considered a treat and not part of regular family meal patterns. However, some families also reported eating fast food more regularly (several times a week), indicating that they did not consider fast food to be part of "dining out." This parallels other studies that have found that children and adolescents are consuming fast food increasingly and it accounts for a large portion of their daily caloric intake $(5,7)$.

331 Coupled with this, an observational study found that fast food restaurant meals were on average lower 332 in calories than non-fast food meals (26). Together, these findings support the continuation of policy efforts impacting large chain restaurants as an obesity prevention strategy. 
335 The impact of kids' menus is far reaching, especially since families in this study allowed their children

336 to order freely from the kids' menu. Children were given a high level of autonomy when deciding what 337 to order from restaurants. It has been described by other interviews with parent-child dyads that food 338 choices are co-constructed between parent and child and nutrition education approaches should take 339 this into consideration (27). Despite a high level of reliance on kids menus from the families that were 340 interviewed, many highlighted the need for improvements to be more healthy (e.g., fruits and 341 vegetables), as well as portioned appropriately.

343 Many parents expressed concern for their child while dining out (i.e., acknowledging kids' menus were 344 less than desirable, role modeling positive dietary behaviors), yet also were challenged by competing 345 interests that limited their healthy choices (e.g., price, what foods their child would eat). Efforts are 346 being made to remedy this. The World Health Organization and the Institute of Medicine have called 347 for tighter controls on marketing unhealthy foods to children $(28,29)$. The food landscape is ever 348 changing and more families are seeking healthier options. This increased consumer demand has likely 349 contributed to corporations making changes. For example, McDonalds recently announced plans to 350 offer more fruits and vegetables at no added cost to meals and to promote milk and juice as beverages 351 for kids' meals (30).

353 However, kids meals (including less healthy ones) are likely not to disappear from menus. One 354 probable reason for reliance on kids menus are they are typically cost controlled for families (i.e., one 355 set price for items from the kids menu). In larger studies, price has been noted as a major determinant 356 of purchasing and consumption (31). Pricing interventions may have promise in ultimately affecting 357 American's weight outcomes (32). Some real world pricing interventions have been tested with 358 children (33), but further research in the restaurant setting is needed to establish ideal pricing and menu 359 options that will be most healthful for consumers.

361 Also highlighted in the current paper is the difference between feeding styles at home when compared 362 to FAFH. Parent participants generally reported allowing more autonomy for their child when selecting 363 meals at a restaurant when compared to rules and guidelines followed at home, acknowledging less 364 healthy meal patterns outside of the home. SSBs represent a large portion of the increase in caloric 365 consumption seen over last few decades (34). Many parent-child dyads in the current study described 366 limiting SSBs at home, but not as much while eating out. In light of our findings, there still remains an 367 opportunity to educate parents about SSBs and providing healthier default offerings on menus. 
Interventions should target differences between FAFH and foods prepared and consumed in the home, 369 perhaps with a focus on decreasing SSB consumption outside of the home.

371 Many participants in the current study indicated consuming meals in front of the TV. Previous studies 372 have documented the benefits of family meal time at a table and not in front of the TV (i.e., in terms of 373 weight, dietary consumption, and social outcomes) (30,31). A concurrent issue, was that parents expressed concern about the marketing influences on their child's food preferences and consumption. Even brief exposures to televised food commercials can influence preschool children's food preferences (37). As children mature, they become independent consumers, making exposure to marketing and development of taste preferences very important in these early years. Therefore interventions aimed at increasing quality family meal time, along with other strategies for increasing consumption of more healthful foods is warranted.

Fostering a more positive nutrition environment via parents and role modeling should also be further examined in the context of consuming more FAFH. Many parents in the current study acknowledged some nutrition knowledge. Golan and colleagues describe a parent's nutrition knowledge as one of the key predictors of the home food environment that helps determine a child's dietary patterns and ultimately body weight $(38,39)$. Role modeling positive dietary behaviors (as obtained through nutrition knowledge) is beneficial and has been demonstrated to results in more healthful dietary patterns and lower BMIs for youth (40).

Parents in the current study engaged in a range of feeding styles. An authoritative feeding style has been shown to be most beneficial in terms of encouraging children to eat dairy, fruit, and vegetables (41). Alternatively, an authoritarian feeding style has been show to be negatively associated with child's vegetable consumption (41). Specific to Latino families, healthy eating has been shown to be greater in children whose parents use positive reinforcement and monitoring, less controlling styles (18).

When comparing English- and Spanish- speaking families in the current study, Spanish-speaking 397 families demonstrated more home cooking and families meals, and less FAFH. Home food availability 398 is a large determinant of meals consumed at home (42), a simple way that parents are influencing their 399 children's meals at home. Previous studies have demonstrated that Latino parents generally have an awareness and understanding of positive feeding styles and tend to cook more traditional foods at 
401 home $(43,44)$. Differences in feeding style between English- and Spanish-speaking parents were also 402 revealed in the current study. Similar to other findings, Spanish speaking families reported dining out 403 fewer times per week and expressed the importance of home cooking, both in terms of tradition and 404 healthfulness $(43,44)$. Despite this, growing rates of health disparities and obesity exist in Latino 405 populations (45). Further studies should explore the cultural value of food in Latino cultures and the 406 resultant dietary behaviors.

407

408 The current study has limitations. The responses from parent-child dyads are only representative of 409 those 20 parent-child dyads ( $\mathrm{N}=40$ participants) sampled in Omaha, NE. However, sampling strategies 410 targeted a diverse audience, including low-income and English or Spanish participants. Children who 411 participated in this study were 8-13 year old and these results may not be generalizable to younger or 412 older age groups. In general, the child interviews were shorter (on average 15 minutes, compared to the 413 adult interviews which averaged 30 minutes), which generated fewer meaning units from the children. 414

415 Decision-making between parent-child dyads about menu ordering at restaurants is complex. Factors 416 span the socioecological model - from the individual level (e.g., taste preferences) to the 417 environmental level (e.g., food marketing). The results of this study can be considered for future 418 research in understanding the decision-making process for English- and Spanish- speaking parent-child 419 dyads when ordering from a restaurant menu. Efforts should include understanding the decision420 making process and influences at every level of the socioecological model. Findings from this study, 421 others, and future research will be valuable for families, restaurant owners, nutrition educators, and 422 policy makers to encourage healthier food choices while eating FAFH in a changing food environment. 423 Further, intervention studies targeting healthy eating and FAFH can be tailored to address some of the 424 nuances in feeding style and parent-child co-decision making. 
425 Table 1. Sociodemographics of participants and key characteristics related to foods consumed outside 426 the home $(\mathrm{N}=40)$

\begin{tabular}{|c|c|c|c|}
\hline \multicolumn{2}{|l|}{ Adults $(n=20)$} & \multicolumn{2}{|l|}{ Children $(n=20)$} \\
\hline Age, $n(\%)$ & & Age, mean (SD) & $10.5(1.6)$ \\
\hline 21 and under & $5(25 \%)$ & & \\
\hline 22 to 34 & $10(50 \%)$ & BMI percentile, mean (SD) & $63(38.55)$ \\
\hline 35 to 44 & $4(20 \%)$ & & \\
\hline Missing & $1(5 \%)$ & $\operatorname{Sex}, n(\%)$ & \\
\hline Education, $n(\%)$ & & Male & $13(65 \%)$ \\
\hline Never Attended & 0 & Female & $7(35 \%)$ \\
\hline Grades 1-8 & $4(20 \%)$ & Latino, $n(\%)$ & \\
\hline Grades 9-11 & $2(10 \%)$ & Yes & $13(65 \%)$ \\
\hline Grades 12 or GED & $2(10 \%)$ & Race, $n(\%)$ & \\
\hline Some College & $3(15 \%)$ & White & $5(25 \%)$ \\
\hline College Graduate & $8(40 \%)$ & Black & $2(10 \%)$ \\
\hline Missing & $1(5 \%)$ & Asian & $1(5 \%)$ \\
\hline Household Income, $n(\%)$ & & American Indian or & $1(5 \%)$ \\
\hline & & Alaskan Native & \\
\hline Less than $\$ 10,000$ & $3(15 \%)$ & Other & $3(15 \%)$ \\
\hline$\$ 10,000-\$ 19,000$ & $3(15 \%)$ & I Don’t Know & $2(10 \%)$ \\
\hline$\$ 20,000-\$ 50,000$ & $7(35 \%)$ & Missing & $4(20 \%)$ \\
\hline$\$ 50,000-\$ 100,000$ & $2(10 \%)$ & & \\
\hline Greater than $\$ 100,000$ & $3(15 \%)$ & & \\
\hline Missing & $2(10 \%)$ & & \\
\hline
\end{tabular}


BMI, mean (SD)

$29.1(6.5)$

Relationship to Child, n (\%)

Mother $15(75 \%)$

Father $4(20 \%)$

Missing $1(5 \%)$

$\operatorname{Sex}, n(\%)$

Male $4(20 \%)$
Female $16(80 \%)$

Latino, $n(\%)$

Yes $11(55 \%)$

Race, $n(\%)$

White $6(30 \%)$

Black $2(10 \%)$

Asian $1(5 \%)$

Other $7(35 \%)$

Missing $4(40 \%)$

Employment Status, $n(\%)$

Employed $12(60 \%)$

Not Employed 7 (35\%)

Missing $1(5 \%)$ 


\begin{tabular}{|c|c|c|}
\hline Theme & Category & Example Meaning Unit \\
\hline Decision making when dining out & $\begin{array}{l}\text { - Choice of restaurant } \\
\text { - Choice of meal for child }\end{array}$ & $\begin{array}{l}\text { "I don't look at the nutrition. Uh, } \\
\text { should, but I don't. I don't really } \\
\text { look at the price for the kids } \\
\text { menu because they're pretty } \\
\text { much the same, set prices, and } \\
\text { just as long as it's something he's } \\
\text { going to eat". }\end{array}$ \\
\hline $\begin{array}{l}\text { Parenting practices and feeding } \\
\text { style }\end{array}$ & $\begin{array}{l}\text { - Mealtime at home } \\
\text { - Concern about child's weight } \\
\text { status } \\
\text { - Food as a reward } \\
\text { - Parents role modeled healthy } \\
\text { dietary behaviors } \\
\text { - Negotiation } \\
\text { - Authoritative Feeding Style } \\
\text { - Control sugar sweetened } \\
\text { beverages consumption } \\
\text { - Overall feeding style } \\
\text { differences of Spanish-speaking } \\
\text { parents }\end{array}$ & $\begin{array}{l}\text { "I'll try to get her to get the } \\
\text { vegetable and she'll want the } \\
\text { French fries. So sometimes what } \\
\text { we'll do, we'll negotiate and one } \\
\text { of us will get the French fries and } \\
\text { one of us will get the vegetables, } \\
\text { and then she'll have a little bit of } \\
\text { it. Like I said, I don't want her } \\
\text { sneaking, I don't want her } \\
\text { feeling, like, I feel like } \\
\text { moderation in everything is a } \\
\text { good idea." }\end{array}$ \\
\hline $\begin{array}{l}\text { Use of and opinions about kid's } \\
\text { menu }\end{array}$ & $\begin{array}{l}\text { - Use of kids menus } \\
\text { - Lack of healthfulness of menu } \\
\text { items and changes wanted } \\
\text { - Decrease portion size } \\
\text { - Child food preferences }\end{array}$ & $\begin{array}{l}\text { "I think that they could have } \\
\text { healthier options, like McDonalds } \\
\text { getting the apples, but I think that } \\
\text { they could have healthier and } \\
\text { maybe not like the fries, they give } \\
\text { them so many fries, sometimes }\end{array}$ \\
\hline
\end{tabular}




\begin{tabular}{|c|c|c|}
\hline & & $\begin{array}{l}\text { they get more fries than I do and } \\
\text { that should be the opposite I } \\
\text { think." }\end{array}$ \\
\hline $\begin{array}{l}\text { Overall influences on food } \\
\text { choices }\end{array}$ & $\begin{array}{l}\text { - Marketing's influence on food } \\
\text { choices } \\
\text { - Child as independent consumer } \\
\text { - Dining out is considered a treat } \\
\text { - Different feeding styles at home } \\
\text { compared to restaurant eating } \\
\text { - Parents concern for nutrition } \\
\text { and nutrition knowledge }\end{array}$ & $\begin{array}{l}\text { "...he is picky, he's a big kid, he } \\
\text { eats what he wants not what you } \\
\text { want, if I give him a salad he will } \\
\text { not eat it at all, if I give him a } \\
\text { hotdog and chips he will eat it } \\
\text { right away, its really difficult, you } \\
\text { live here in American its more } \\
\text { hard there are more commercials } \\
\text { all the time and kid want to eat at } \\
\text { fast food". }\end{array}$ \\
\hline
\end{tabular}


- Acculturation

- Family dining habits at home and outside of the home

- Parental policies and role modeling related to food

- Child as an independent consumer

- Restaurant ordering behaviors (level of autonomy)

- Perceptions of healthy versus unhealthy foods

- Perceptions of options available on kids menus

- Marketing influences on dietary choices

Figure 1. Domains of Inquiry For Influences on Food Away from Home Among English- and SpanishSpeaking Parent-Child Dyads 
1. Bowman SA, Gortmaker SL, Ebbeling CB, et al. (2004) Effects of Fast-Food Consumption on Energy Intake and Diet Quality Among Children in a National Household Survey. Pediatrics 113(1), 112-8.

2. Katz DL. (2010) Unfattening our children: forks over feet. Int J Obes 35(1), 33-37.

3. Drewnowski A. (2010) The cost of US foods as related to their nutritive value. Am J Clin Nutr 92(5):1181-8.

4. Putnam J, Allshouse J, Kantor LS. (2002) U.S. Per Capita Food Supply Trends: More Calories, Refined Carbohydrates, and Fats. Food Rev 25(3), 2-15.

5. Kant AK, Graubard BI. (2004) Eating out in America, 1987-2000: trends and nutritional correlates. Prev Med 38(2), 243-249.

6. Todd JE, Mancino L, Lin B-H. (2010) The Impact of Food Away from Home on Adult Diet Quality [Internet]. Rochester, NY: Social Science Research Network; Report No.: ID 1557129. Available from: http://papers.ssrn.com/abstract=1557129

7. Mancino L. (2010) How Food Away From Home Affects Children's Diet Quality. United States Department of Agriculture.

8. Boutelle KN, Fulkerson JA, Neumark-Sztainer D, et al. (2007) Fast food for family meals: relationships with parent and adolescent food intake, home food availability and weight status. Public Health Nutr 10(01), 16-23.

9. Labrecque J, Ricard L. (2001) Children's influence on family decision-making: a restaurant study. J Bus Res 54(2), 173-176.

10. Ventura A, Birch L. (2008) Does parenting affect children's eating and weight status? Int J Behav Nutr Phys Act 5(1), 15.

11. Vereecken C, Legiest E, De Bourdeaudhuij I, et al. (2009) Associations between general parenting styles and specific food-related parenting practices and children's food consumption. Am J Health Promot 23(4), 233-240.

12. Eisenberg CM, Ayala GX, Crespo NC, et al. (2012) Examining Multiple Parenting Behaviors on Young Children's Dietary Fat Consumption. J Nutr Educ Behav 44(4), 302-309.

13. Baumrind D. The influence of parenting style on adolescent competence and substance use. J Early Adolesc. 1991;11(1):56-95.

14. Maccoby EE, Martin JA. (1983) Socialization in the context of the family: Parent-child interaction. Handb Child Psychol 4, 100-101. 
467

468

469

470

471

472

473

474

475

476

477

478

479

480

481

482

483

484

485

486

487

488

489

490

491

492

493

494

495

496

497

498

499

500

501

502

15. Hughes SO, Power TG, Orlet Fisher J, et al. (2005) Revisiting a neglected construct: parenting styles in a child-feeding context. Appetite 44(1), 83-92.

16. Chaidez V. (2009) Toddler feeding practices in Latinos: An early start in obesity prevention. 70 $(9)$.

17. Duerksen SC, Elder JP, Arredondo EM, et al. (2007) Family Restaurant Choices Are Associated with Child and Adult Overweight Status in Mexican-American Families. J Am Diet Assoc 107(5), 849-853.

18. Arredondo EM, Elder JP, Ayala GX, et al. (2006) Is parenting style related to children's healthy eating and physical activity in Latino families? Health Educ Res 21(6), 862-871.

19. French SA, Story M, Neumark-Sztainer D, et al. (2001) Fast food restaurant use among adolescents: associations with nutrient intake, food choices and behavioral and psychosocial variables. Int $J$ Obes 25(12), 1823-1833.

20. Nielsen SJ, Siega-Riz AM, Popkin BM. (2002) Trends in Food Locations and Sources among Adolescents and Young Adults. Prev Med 35(2), 107-113.

21. Kaufman L, Karpati A. (2007) Understanding the sociocultural roots of childhood obesity: food practices among Latino families of Bushwick, Brooklyn. Soc Sci Med 64(11), 2177-2188.

22. Cresswell JW. (2007) Qualitative inquiry and research design: Choosing among five approaches. Sage.

23. Parry KW. (2003) Constant comparison. Sage

24. Wu HW, Sturm R. (2013) What's on the menu? A review of the energy and nutritional content of US chain restaurant menus. Public Health Nutr 16(01), 87-96.

25. Poti JM, Slining MM, Popkin BM. (2013) Solid Fat and Added Sugar Intake Among US Children: The Role of Stores, Schools, and Fast Food, 1994-2010. Am J Prev Med 45(5), 551559 .

26. Serrano EL, Jedda VB. (2009) Comparison of Fast-Food and Non-Fast-Food Children's Menu Items. J Nutr Educ Behav 41(2), 132-137.

27. Bassett R, Chapman GE, Beagan BL. (2008) Autonomy and control: The co-construction of adolescent food choice. Appetite, 50(2-3), 325-332.

28. WHO urges tougher food marketing rules to curb childhood obesity [Internet]. GlobalPost. [cited $2013 \mathrm{Jul}$ 8]. Available from: http://www.globalpost.com/dispatch/news/thomsonreuters/130618/who-urges-tougher-food-marketing-rules-curb-childhood-obesity

29. Accelerating Progress in Obesity Prevention - Institute of Medicine [Internet]. [cited 2012 Aug 8]. Available from: http://www.iom.edu/Activities/Nutrition/ObesityPrevProgress.aspx

30. Jargon J. McDonald's to Offer Alternatives to Fries, Sodas. Wall Str J [Internet]. 2013 Sep 26 [cited 2013 Oct 1]; Available from: http://online.wsj.com/article/SB10001424052702304526204579099590953728228.html 
503

504

505

506

507

508

509

510

511

512

513

514

515

516

517

518

519

520

521

522

523

524

525

526

527

528

529

530

531

532

533

534

535

31. Andreyeva T, Long MW, Brownell KD. (2010) The Impact of Food Prices on Consumption: A Systematic Review of Research on the Price Elasticity of Demand for Food. Am J Public Health 100(2), 216-222.

32. Powell LM, Chaloupka FJ. (2009) Food Prices and Obesity: Evidence and Policy Implications for Taxes and Subsidies. Milbank Q 87(1), 229-257.

33. Glanz K, Bader MDM, Iyer S. (2012) Retail Grocery Store Marketing Strategies and Obesity: An Integrative Review. Am J Prev Med 42(5), 503-512.

34. Popkin BM, Nielsen SJ. (2003) The Sweetening of the World's Diet. Obes Res 11(11), 13251332.

35. Hammons AJ, Fiese BH. (2011) Is Frequency of Shared Family Meals Related to the Nutritional Health of Children and Adolescents? Pediatrics 127(6), e1565-e1574.

36. Fulkerson JA, Story M, Neumark-Sztainer D, et al. (2008) Family Meals: Perceptions of Benefits and Challenges among Parents of 8- to 10-Year-Old Children. J Am Diet Assoc 108(4), 706-709.

37. Borzekowski DLG, Robinson TN. () The 30-second effect: An experiment revealing the impact of television commercials on food preferences of preschoolers. J Am Diet Assoc 101(1), 42-46.

38. Golan M, Weizman A. (2001) Familial approach to the treatment of childhood obesity: conceptual mode. J Nutr Educ 33(2), 102-107.

39. Golan M, Crow S. (2004) Parents are key players in the prevention and treatment of weightrelated problems. Nutr Rev 62(1), 39-50.

40. Benton D. (2004) Role of parents in the determination of the food preferences of children and the development of obesity. Int J Obes 28(7), 858-869.

41. Patrick H, Nicklas TA, Hughes SO, et al. (2005) The benefits of authoritative feeding style: caregiver feeding styles and children's food consumption patterns. Appetite 44(2), 243-250.

42. Pearson N, Biddle SJ, Gorely T. (2009) Family correlates of fruit and vegetable consumption in children and adolescents: a systematic review. Public Health Nutr 12(2), 267.

43. Evans A, Chow S, Jennings R, et al. (2011) Traditional Foods and Practices of Spanish-Speaking Latina Mothers Influence the Home Food Environment: Implications for Future Interventions. $J$ Am Diet Assoc 111(7), 1031-1038.

44. Gomel JN, Zamora A. (2007) English-and Spanish-speaking Latina mothers' beliefs about food, health, and mothering. J Immigr Minor Health 9(4), 359-367.

45. Flegal KM, Ogden CL, Yanovski JA, et al. (2010) High adiposity and high body mass index-forage in US children and adolescents overall and by race-ethnic group. Am J Clin Nutr 91(4), 1020 1026. 